\title{
Review of school vision screening guidelines
}

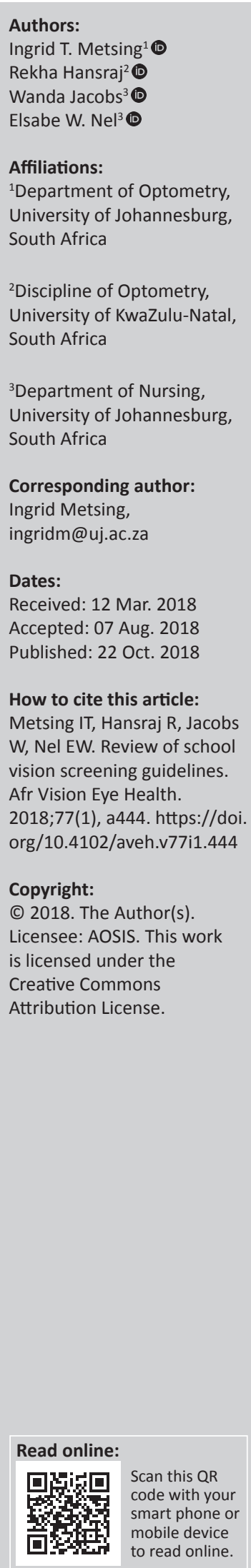

Background: Vision screenings are important in identifying visual anomalies likely to disrupt the physical, intellectual, social and emotional development of children. School health services globally include vision screenings, complementing a variety of associated screening services.

Aim: This review article provides evidence for content, provision and efficacy of the vision screening services for children of school-going age and reports on the current practice of children's vision screenings worldwide including in South Africa.

Methods: Studies were identified from PubMed, Ebscohost and Science Direct with the search terms utilised during the selection of electronic articles and journals for the review. The target population includes children of school-going age from 6 to 19 years without previously known conditions associated with visual anomalies and learning-related problems. The quality of vision screening programmes and policies for the school-going age children in different countries were evaluated using Wilson and Jungner criteria. ${ }^{1}$

Results: Vision screening programmes worldwide appear to support comprehensive vision screening methods among pre-schoolers (from birth to $\leq 6$ years vs. children of school-going age). The development of vision screening procedures in some countries in the United States of America (USA) was found to be grounded on epidemiologic findings and principles. These may have contributed towards the formulation of national vision screening guidelines for preschoolers that supported the detection of amblyopia and its associated conditions such as strabismus, anisometropia and myopia. School-going children's vision screenings are not supported worldwide as research has shown that there is lack of benefits for detecting other visual anomalies such as vergence and accommodative dysfunctions. This is despite evidence provided by the literature reviewed that an association exists between prevalent accommodation and vergence dysfunctions including poor ocular motilities and poor near-vision, among children of school-going age with poor academic performance.

Conclusion: The guidelines worldwide support school vision screenings, especially for the pre-schoolers by the school health nurses, with other programs having considered the teachers, optometrists or orthoptists as the appropriate personnel to conduct the school vision screenings. There is still a need for the effectiveness of the school vision-screening programmes to be investigated related to the importance of detecting convergence and accommodative dysfunctions for the school going age children.

\section{Introduction}

The purpose of the school vision screenings is to detect visual anomalies that may disrupt the physical, intellectual, social and emotional development of children. ${ }^{2}$ Approximately one in five school children has visual anomalies, with the highest rates from poor social backgrounds. ${ }^{3,4}$ There are debates worldwide on the nature of test batteries to be included in the vision screening programmes, appropriate vision screening personnel, cost effectiveness and the ideal screening age. ${ }^{5,6,7}$ The value of school vision screenings for detecting visual anomalies such as accommodative and vergence dysfunctions, ocular health problems and refractive errors (latent) is questioned worldwide, despite evidence supporting the association of these conditions with poor academic performance. ${ }^{8,9,10,11}$

Evidence indicates that the targeted visual anomaly in most school vision screening programmes, especially in pre-schoolers, is amblyopia and its associated conditions such as strabismus and refractive errors (e.g. myopia). $5,6,7$ However, worldwide, the prevalence of amblyopia in the school-going age population was found to range between approximately $0.73 \%$ and $7.3 \%, 12,13,14,15$ less compared to the prevalence of uncorrected hyperopia $(0.26 \%-73.1 \%))^{16,17,18,19}$ convergence insufficiency $(1.6 \%-28.0 \%)^{20,21,22,23}$ and accommodative dysfunction $\left.(0.6 \%-40.0 \%)\right)^{20,21,22,23,24,25}$ Nevertheless, the beneficence of early detection (e.g. infants and pre-schoolers) of amblyopia is 
supported by most countries in line with successful remediation of the condition, hence the prioritising of the detection of reduced distance vision by most vision screening protocols.

Prioritising the detection of reduced distance vision appears to likely miss children not seeing clearly at near or those that may be suffering from symptoms not addressed by distance visual acuity (VA) screenings such as poor oculomotor, accommodative and vergence dysfunctions. Arguably, these visual anomalies are reported to be strongly related to reading and writing. ${ }^{8,9,10,11}$ Nonetheless, the variance of the prevalence of non-strabismic anomalies (such as convergence insufficiency and accommodative dysfunctions) was found to be because of the different diagnostic criteria, special characteristics of the population or the clinical methods used. ${ }^{7}$ However, in the interest of this literature review, the detection of reduced VAs at distance and near (which could be because of amblyopia, ametropia, anisometropia and strabismus) including accommodative and vergence anomalies when school vision screenings are conducted will be discussed.

In order to gather an evidence base for content and provision of the vision screening services for children of the schoolgoing age population, the policies and guidelines of different countries will be reviewed and discussed.

\section{Methods}

\section{Policies on schools vision screenings}

Globally, vision screening policies, guidelines and requirements show considerable variation, and there appears to be a lack of standardisation of school vision screening programmes. ${ }^{6,7}$ Areas of differences needing consideration are legislation, visual functions assessed (the nature of tests), criteria for referral, ideal age (frequency of screening) and vision screening personnel.

\section{Legislation}

In the USA, country-wide mandatory legislation ensuring the screening of all children for visual anomalies prior to school entry, with appropriate follow-up eye examinations when necessary, is supported by Prevent Blindness America. There are varied responses from different states towards preventive policies and promotion of healthy vision for children of school-going age. For example, the states of Arizona, Idaho, Montana, New Hampshire, South Carolina, Wisconsin, and North and South Dakota do not appear to have preventive policies requiring vision screening before entry into school, while others have mandated state laws. ${ }^{6,26,27}$

Kentucky, Missouri and Illinois are the only states requiring a vision examination by an optometrist or ophthalmologist for all children enrolled in public preschools (3-6 years), public preschool or in the 'Head Start' programme (nursery school). Vision screenings are also conducted on children of school-going age, especially those identified by their school teachers as having visual problems, those struggling with learning activities and those transferred to new schools. Evidence in the form of certification is a requirement in most of the countries legislated to conduct school vision screenings. The certification is to be submitted to the schools on specific dates to ensure that the vision examinations and vision screenings conducted meet the prescribed requirements of various US states (Kentucky, Missouri and Illinois). Furthermore, the submission of evidence appears to be related to the safe keeping of epidemiological data that could contribute towards the formulation of the national vision screening guidelines..$^{27,28}$

Although school-going children's vision screenings are supported by governments in countries such as the United Kingdom, Canada, Australia, East Mediterranean countries and South Africa, they are not mandatory. ${ }^{29,30,31,32,33,34}$ In Oman and Saudi Arabia, screening programmes focus on locally endemic diseases affecting the eyes of children from poor communities, caused by vitamin A deficiency, trachoma and viral conjunctivitis and on the detection of amblyopia. ${ }^{31}$ In countries where no legislative or regulatory requirements for children's vision screenings are available, support can generally be found in the country's special education laws. ${ }^{26}$ Lack of legislated school vision screenings has led to screenings conducted on an ad hoc manner by optometrists in private practice, orthoptists, medical practitioners and ophthalmologists, resulting in unmeasured and inconsistent service provision. This seems to have contributed towards the considerable variations on the tests, age, frequency and the target conditions to be detected when the school vision screenings are conducted.

\section{Screening age}

There are ongoing debates relating to the ideal age at which the vision screenings should be conducted. The main focus of the majority of the vision screening protocols supports vision screening of pre-schoolers for the detection of amblyopia and for early detection and remediation of risk factors such as strabismus and refractive errors. ${ }^{29,30,32,33,34,35,36}$ Nonetheless, the purpose of vision screening on school-going age children is to detect visual problems, which may impair reading efficiency and learning of those at the risk of developing agerelated visual problems. The preschool population is included in this literature review because most schools (e.g. in South Africa) include this age group in their environments.

In a recent policy statement, the American Academy of Optometry recommended that vision screenings ought to be available throughout childhood, from birth to preschool ( $\leq 6$ years) including children of school-going age ( $\geq 6$ years). ${ }^{37}$ In the USA, most screening protocols include children from preschool to school-going age. ${ }^{27}$ The ages at which children's vision screenings are conducted differ in each state or country (Table 1), with different guidelines used such as the Bright Futures Guidelines and Child and Teen Checkups (CTC) periodicity schedules. ${ }^{38,39}$ Despite the visual examinations required in Kentucky, vision screenings are also required one 
TABLE 1: International and national guidelines on children's vision screenings

\begin{tabular}{|c|c|c|c|c|c|}
\hline $\begin{array}{l}\text { States (of USA) } \\
\text { or countries }\end{array}$ & Vision screening tests & Grades & Additional methods & Referral criteria & Screening personnel \\
\hline Alaska, USA ${ }^{55}$ & $\begin{array}{l}\text { - Observation (ABC) } \\
\text { checklist } \\
\text { - DVAs: Sloan, LEA symbols } \\
\text { or HOTV Lighthouse } \\
\text { - NVAs: Plus Lens Test: } \\
\text { +2.50 or near charts } \\
\text { - Cover test or Hirschberg } \\
\text { - Stereo test } \\
\text { - Colour vision test }\end{array}$ & $\begin{array}{l}\text { R, 1-12 } \\
\text { Bright futures } \\
\text { Peridiocity }\end{array}$ & $\begin{array}{l}\text { - Photoscreeners } \\
\text { - Auto refractors }\end{array}$ & $\begin{array}{l}\text { - } 20 / 40 \text { or worse: } \leq 6 \text { years } \\
\text { - } 20 / 30 \text { or worse: } \geq 6 \text { years } \\
\text { - } 2 \text {-line difference between the eyes } \\
\text { - Cover Test: any eye movements } \\
\text { - Hirschberg: unequal light reflexes } \\
\text { - Stereo Acuity: gross reduced } \\
\text { stereoacuity }\end{array}$ & $\begin{array}{l}\text { - Public health nurses } \\
\text { - Private providers } \\
\text { (e.g. optometrists) }\end{array}$ \\
\hline Arizona, USA ${ }^{68}$ & $\begin{array}{l}\text { - Observation (ABC) } \\
\text { checklist } \\
\text { - } \text { DVAs: LEA symbols, } \\
\text { ETRDS } \\
\text { - NVA: optional ( } \geq \text { Gr. 5) } \\
\text { - Stereo test } \\
\text { - Colour vision }\end{array}$ & $\mathrm{R}-4, \geq 5$ & $\begin{array}{l}\text { - Automated } \\
\text { Computerised Screener: } \\
\text { Eyespy } 20 / 20 \\
\text { - Plus Optix } \\
\text { - Photoscreener }\end{array}$ & $\begin{array}{l}\text { - } 20 / 40 \text { or worse: } \leq 6 \text { years } \\
\text { - } 20 / 30 \text { or worse: } \geq 6 \text { years } \\
\text { - 2-line difference between the eyes } \\
\text { - Colour vision, Stereoacuity } \\
\text { Manufacturer's manual }\end{array}$ & - Trained personnel \\
\hline Australia $^{29}$ & $\begin{array}{l}\text { DVA: Sheridan Linear Vision } \\
\text { Chart }\end{array}$ & $\mathrm{R}$, Younger & & $6 / 9-6 / 12$ or worse & Orthoptists \\
\hline $\begin{array}{l}\text { British } \\
\text { Columbia }^{30,50}\end{array}$ & $\begin{array}{l}\text { DVA or NVA: a few health } \\
\text { units use VA stereopsis }\end{array}$ & Younger than Gr R & $\begin{array}{l}\text { - Welch Allyn SureSight } \\
\text { Vision Screener }\end{array}$ & $\begin{array}{l}\text { - Sphere: } \leq-1.0 \mathrm{D} \text { or } \geq+3.0 \\
\text { - Cylinder: } \geq 1.5 \mathrm{D} \\
\text { - Difference: } \geq 1.5 \mathrm{D} \\
\text { - Stereotest: } 100 \text { of arc or worse } \\
\text { - DVA or NVA: } 6 / 12 \text { or worse } \\
\text { - Difference between eyes (Gr R, } \\
\text { younger) DVA or NVA: } 6 / 9 \text { or worse, } \\
\text { difference between eyes (Gr } 1 \text {, older) }\end{array}$ & $\begin{array}{l}\text { - Public health nurses } \\
\text { - Health unit aides } \\
\text { - Trained screeners } \\
\text { - Trained first nations } \\
\text { community health staff }\end{array}$ \\
\hline $\begin{array}{l}\text { California, } \\
\text { USA }^{56}\end{array}$ & $\begin{array}{l}\text { - Observation (ABC) } \\
\text { checklist } \\
\text { - DVA: illiterate 'E' Charts, } \\
\text { Blackbird, HOTV with } \\
\text { crowding bars, LEA } \\
\text { symbols } \\
\text { - Plus lens test: }+2.50 \\
\text { - Cover test or Hirschberg } \\
\text { - Stereo test } \\
\text { - Colour vision test }\end{array}$ & $R, 1-3,5,7,9$ & $\begin{array}{l}\text { - Stereoscopic testing } \\
\text { instruments (e.g. Titmus } \\
\text { or keystone vision } \\
\text { testers) }\end{array}$ & $\begin{array}{l}\text { - } 6 / 15 \text { or worse: } \leq 6 \text { years } \\
\text { - } 6 / 12 \text { or worse: } \geq 6 \text { years } \\
\text { - } 2 \text {-line difference between the eyes } \\
\text { - Cover Test: any eye movements } \\
\text { - Hirschberg: unequal light reflexes } \\
\text { - Stereo Acuity: gross reduced } \\
\text { stereoacuity } \\
\text { - Colour vision: manual guidelines }\end{array}$ & $\begin{array}{l}\text { - Medical practitioners, } \\
\text { nurse, physician, } \\
\text { ophthalmologist or } \\
\text { optometrist who holds } \\
\text { both (1) a license from the } \\
\text { appropriate California } \\
\text { board or agency } \\
\text { - Certificated school district } \\
\text { or county employees } \\
\text { holding a teaching } \\
\text { credential and are } \\
\text { qualified by training }\end{array}$ \\
\hline \multirow[t]{2}{*}{ Canada $^{30,49}$} & $\begin{array}{l}\text { - A complete examination } \\
\text { of the skin and external } \\
\text { eye structures red reflex } \\
\text { - Hirschberg } \\
\text { - Cover-uncover test } \\
\text { - Fixation and following a } \\
\text { target are observed } \\
\text { DVA or NVA: LogMar, } \\
\text { HOTV, Allen Charts }\end{array}$ & Birth to Gr R & - None & - Not mentioned & $\begin{array}{l}\text { - Non-ophthalmological } \\
\text { personnel, with minimal } \\
\text { training } \\
\text { - Physicians } \\
\text { - School health nurses }\end{array}$ \\
\hline & $\begin{array}{l}\text { - Screen as above } \\
\text { whenever routine health } \\
\text { exams are conducted or } \\
\text { when there are } \\
\text { complaints }\end{array}$ & $1-12$ & & & \\
\hline Georgia, USA ${ }^{70}$ & - DVA: HOTV & $1,4,7,10$ & $\begin{array}{l}\text { - Titmus or Spotscreener } \\
\text { (optional) }\end{array}$ & - $6 / 12(20 / 40)$ or worse & $\begin{array}{l}\text { - Physician } \\
\text { - Local health department } \\
\text { - Optometrist } \\
\text { - 'Prevent Blindness } \\
\text { - Georgia' employee } \\
\text { - School registered nurse }\end{array}$ \\
\hline $\begin{array}{l}\text { Colorado, } \\
\text { USA }^{57}\end{array}$ & $\begin{array}{l}\text { - Observation checklist } \\
\text { - DVA: Snellen, HOTV, LEA } \\
\text { symbols, Tumbling CS, Es, } \\
\text { Allen pictures } \\
\text { - NVA: Lea symbols or } \\
\text { Sloan letters } \\
\text { - Plus lens test } \\
\text { - Near-point of } \\
\text { convergence Test } \\
\text { - Alternate cover test } \\
\text { - Stereopsis test } \\
\text { - Colour vision test }\end{array}$ & $\begin{array}{l}R, 1-3,5,7,9 \\
R \text { or } 1 \\
\text { New, referred }\end{array}$ & $\begin{array}{l}\text { - McDowell vision } \\
\text { screening kit } \\
\text { - Stereoscope machine } \\
\text { (e.g. Keystone } \\
\text { Telebinocular) } \\
\text { - Computer software } \\
\text { - Photorefractive images }\end{array}$ & $\begin{array}{l}\text { - DVA or NVA: } 6 / 9 \text { or worse } \\
\text { - NPC: unable to converge to at least } 3 \\
\text { inches from the bridge of the nose } \\
\text { - Cover Test: consistent horizontal, } \\
\text { vertical or diagonal movement of the } \\
\text { covered or uncovered }\end{array}$ & $\begin{array}{l}\text { - School health nurses } \\
\text { - Trained lay personnel }\end{array}$ \\
\hline $\begin{array}{l}\text { Connecticut, } \\
\text { USA }^{69}\end{array}$ & $\begin{array}{l}\text { - Observation checklist } \\
\text { - Snellen chart, illiterate } \\
\text { Es, HOTV, LEA symbols }\end{array}$ & $\begin{array}{l}\mathrm{R}, 1-6,9 \\
\text { Bright futures periodicity }{ }^{33}\end{array}$ & - None & $\begin{array}{l}\text { - } 6 / 9 \text { or worse } \leq 8 \text { years } \\
\text { - Worse than } 6 / 6 \geq 9 \text { years } \\
\text { - } 2 \text {-line difference between the eyes }\end{array}$ & $\begin{array}{l}\text { - Properly trained health } \\
\text { aides or volunteers } \\
\text { - Supervisors: school nurse } \\
\text { or school medical advisor }\end{array}$ \\
\hline lowa, USA ${ }^{58}$ & $\begin{array}{l}\text { Observation checklist } \\
\text { - DVA: LEA symbols } \\
\text { - Stereopsis } \\
\text { - ETRDS } \\
\text { - Plus lens test: }+2.50 \\
\text { - Colour vision test }\end{array}$ & $1,3,5$ & - Photoscreening & $\begin{array}{l}\text { - } 6 / 15 \text { or worse } \leq 5 \text { years } \\
\text { - } 6 / 12 \text { or worse } \geq 6 \text { years } \\
\text { - } \geq 2 \text {-line difference between the eyes } \\
\text { resultity of screener to obtain test } \\
\text { - Stereo Test: failure to perform step } 2 \\
\text { of the procedure } \\
\text { - Failure of the plus lens test }\end{array}$ & $\begin{array}{l}\text { - School nurses } \\
\text { - Teachers } \\
\text { - Vision screening } \\
\text { technicians } \\
\text { - Trained lay volunteers. }\end{array}$ \\
\hline
\end{tabular}


TABLE 1 (Continues...): International and national guidelines on children's vision screenings.

\begin{tabular}{|c|c|c|c|c|c|}
\hline $\begin{array}{l}\text { States (of USA) } \\
\text { or countries }\end{array}$ & Vision screening tests & Grades & Additional methods & Referral criteria & Screening personnel \\
\hline $\begin{array}{l}\text { Minnesota, } \\
\text { USA }^{39}\end{array}$ & $\begin{array}{l}\text { - Observation checklist } \\
\text { - DVA or NVA: Sloan } \\
\text { letters Chart, LEA } \\
\text { symbols, HOTV } \\
\text { - Plus lens test: } \\
\text { - }+2.25: \text { Gr } 1-3 \\
\text { - } 1.75: \text { Gr } 3,4 \\
\text { - Colour vision test: } \\
\text { Gr R Men only } \\
\text { - Hirschberg } \\
\text { - Unilateral cover test } \\
\text { - at far, near } \\
\text { - Stereo Test: 3rd Grade } \\
\text { - Red reflex } \\
\text { - Pupillary responses }\end{array}$ & $\begin{array}{l}\text { Child and teen checkups } \\
\text { (CTC) }^{34}\end{array}$ & $\begin{array}{l}\text { - Autorefractors } \\
\text { - Photoscreeners }\end{array}$ & $\begin{array}{l}\text { - DVA or NVA: } 6 / 12 \text { or worse } \geq 5 \text { years } \\
\text { - Failure of plus lens test } \\
\text { - Colour vision: manual guidelines } \\
\text { - Cover Test } \\
\text { - Pupillary responses: unequal or } \\
\text { - sluggish response to light. } \\
\text { - Pupils unequal in size or not round. }\end{array}$ & $\begin{array}{l}\text { - Nurses, including public } \\
\text { health and school nurses. } \\
\text { - Ophthalmic or optometric } \\
\text { staff. } \\
\text { - Other trained medical } \\
\text { personnel. }\end{array}$ \\
\hline $\begin{array}{l}\text { New York, } \\
\text { USA }^{46}\end{array}$ & $\begin{array}{l}\text { - Observation checklist } \\
\text { - DVA: Snellen, HOTV, } \\
\text { LEA Symbols, Tumbling } \\
\text { Cs, Es, Allen pictures } \\
\text { - NVAs: +2.25 } \\
\text { - Colour vision test } \\
\text { - Stereopsis test }\end{array}$ & $\mathrm{R}-7,10$ & - None & $\begin{array}{l}\text { - } 6 / 12 \text { or worse: Gr R } \\
\text { - } 6 / 9 \text { or worse: Gr } 1-10 \\
\text { - Failure of plus lens } \\
\text { - Colour vision or Stereopsis test: } \\
\text { manual guidelines }\end{array}$ & - School health nurses \\
\hline New Zealand ${ }^{29}$ & $\begin{array}{l}\text { - VA at } 6 \mathrm{~m} \text { with Sheridan } \\
\text { Gardiner linear vision } \\
\text { chart }\end{array}$ & School entry (Gr 1 ) & - None & - VAs: $6 / 9$, worse & - Health nurses \\
\hline Ohio, USA ${ }^{61}$ & $\begin{array}{l}\text { - Observation checklist } \\
\text { - DVA: Sloan charts, LEA } \\
\text { symbols VIP single, } \\
\text { crowded } \\
\text { - NVA: Sloan charts, } \\
\text { LEA symbols VIP } \\
\text { single, crowded } \\
\text { (optional) } \\
\text { - Modified clinical } \\
\text { techniques (optional) } \\
\text { - Stereopsis test } \\
\text { - Colour vision tests }\end{array}$ & $R, 1,3,5,7,9,11$ & $\begin{array}{l}\text { - Suresight Vision } \\
\text { Screener; } \\
\text { - Retinomax Vision } \\
\text { Screener; } \\
\text { - JAEB Vision Screener }\end{array}$ & $\begin{array}{l}\text { - DVA or NVA: } 6 / 12(20 / 40) \text { or worse } \\
\text { for all age groups } \\
\text { - 2-line difference between the eyes } \\
\text { - MCT: failure criteria } \\
\text { - Stereopsis and colour vision tests: } \\
\text { manual guidelines }\end{array}$ & $\begin{array}{l}\text { Physician, ophthalmologist. } \\
\text { optometrist, optician, } \\
\text { registered nurse } \\
\text { (RN):Nurses may delegate } \\
\text { vision services to a trained } \\
\text { unlicensed personnel }\end{array}$ \\
\hline $\begin{array}{l}\text { Pennsylvania, } \\
\text { USA }^{59}\end{array}$ & $\begin{array}{l}\text { - DVA or NVA: Snellen } \\
\text { chart, symbol 'E' } \\
\text { chart or Tumbling 'E', } \\
\text { HOTV, LEA symbols, } \\
\text { tumbling hand } \\
\text { - Plus lens test: }+2.25 \\
\text { - Colour vision test } \\
\text { - Stereotest }\end{array}$ & $\begin{array}{l}1 \text { or } 2 \text { meeting criteria } \\
\text { New students not } \\
\text { previously screened }\end{array}$ & $\begin{array}{l}\text { - Automated Vision } \\
\text { Screener (Titmus, Optec, } \\
\text { etc.) }\end{array}$ & $\begin{array}{l}\text { - DVA or NVA: } 6 / 12 \text { or worse } \leq 6 \text { years } \\
\text { DVA/NVA: } 6 / 9 \text { or worse } \geq 6 \text { years } \\
\text { - 2-line difference between eyes } \\
\text { - Cover test: any unilateral eye } \\
\text { movements } \\
\text { - Stereoacuity: absence of gross } \\
\text { stereoacuity }\end{array}$ & $\begin{array}{l}\text { - Certified school nurse, } \\
\text { medical technician (health } \\
\text { room aide) or teacher }\end{array}$ \\
\hline South Africa ${ }^{63}$ & $\begin{array}{l}\text { - DVA or NVA: Snellen } \\
\text { chart, Tumbling Es } \\
\text { - Near-point of } \\
\text { convergence test } \\
\text { - External observation } \\
\text { of the eyes }\end{array}$ & R or $1,4,8$ & - None & - DVA or NVA: 6/9 or worse & $\begin{array}{l}\text { - School health nurses, } \\
\text { optometrists, } \\
\text { ophthalmologists, optical } \\
\text { dispensers, medical } \\
\text { practitioners }\end{array}$ \\
\hline \multirow[t]{3}{*}{ Sweden ${ }^{33}$} & $\begin{array}{l}\text { - History: hereditary } \\
\text { factors } \\
\text { - Red Fundus Reflex } \\
\text { - Eyes observation } \\
\text { - Ocular movements } \\
\text { - Fixation behaviour } \\
\text { - Hirschberg }\end{array}$ & $R$, Younger & - None & - Not mentioned & - School health nurses \\
\hline & - DVA: E-chart @ 5m & 1 & & & \\
\hline & $\begin{array}{l}\text { - DVA: Monoyers linear } \\
\text { letters @ 5m }\end{array}$ & 4 & & & \\
\hline $\begin{array}{l}\text { Tennessee, } \\
\text { USA }^{60}\end{array}$ & $\begin{array}{l}\text { - DVA: Snellen chart, LEA } \\
\text { Symbols or HOTV } \\
\text { - NVA: reduced Snellen } \\
\text { chart, LEA symbols or } \\
\text { HOTV or } \\
\text { - Plus lens test:+2.00, } \\
\text { colour vision test }\end{array}$ & Pre-R, R, 2, 4, 6, 8 & $\begin{array}{l}\text { - Keystone Telebinocular } \\
\text { test: muscle balance for } \\
\text { depth Perception }\end{array}$ & $\begin{array}{l}\text { - } 6 / 12 \text { or worse: } \leq 6 \text { years } \\
\text { - } 6 / 9 \text { or worse: } \geq 6 \text { years } \\
\text { 2-line difference between eyes } \\
\text { - Colour vision test: manufacturer's } \\
\text { guidelines }\end{array}$ & $\begin{array}{l}\text { - Trained: } \\
\text { - Student nurses } \\
\text { - Community-based nurses } \\
\text { - Health science instructors } \\
\text { - Clinical instructors } \\
\text { - School nurses } \\
\text { - Other community-based } \\
\text { volunteers }\end{array}$ \\
\hline $\begin{array}{l}\text { United } \\
\text { Kingdom² }\end{array}$ & - LogMar Crowded test & Pre- $R, R$ & - & - $6 / 18$ or worse & - Orthoptists \\
\hline \multirow[t]{2}{*}{$\begin{array}{l}\text { Queensland, } \\
\text { Australia }^{29}\end{array}$} & $\begin{array}{l}\text { Comprehensive vision } \\
\text { screening } \\
\text { - Hirschberg test, } \\
\text { distance and near } \\
\text { cover test, } \\
\text { vision: LEA or HOTV or } \\
\text { STYCAR }\end{array}$ & $\mathrm{R}$, Younger & - None & - Not mentioned & $\begin{array}{l}\text { - Child health nurse } \\
\text { - Health nurse }\end{array}$ \\
\hline & $\begin{array}{l}\text { - Observation checklist } \\
\text { DVA: Snellen chart, } \\
\text { HOTV or LEA symbols } \\
\text { chart }\end{array}$ & $1-12$ & & & \\
\hline
\end{tabular}

LEA \& HOTV, visual acuity charts for children; NVA, near visual acuity chart; DVA, distance visual acuity chart; ETRDS, early treatment diabetic retinopathy study visual acuity chart; Gr, grade; VIP, vision in pre-schoolers; STYCAR, screening test for young children and retardates; ABC, appearance, behavioural observations and complaints. 
year prior to entry into the sixth and ninth grades.,26 Vision screenings are recommended by the Bright Futures Guidelines at ages 3, 4, 5, 6, 8, 10,12, 15 and 18 years, and risk assessment at alternate ages. ${ }^{38}$

In the USA, the consensus on most vision screening protocols seems to be that screenings are to be conducted on all those new to the school system, and on students at high-risk (those repeating grades and in 'special education programmes'), including those transferred from other schools. In addition, a comprehensive vision screening that includes all tests is recommended only once during a student's career, in preschool or Grade 1, or for high-risk students, including those repeating a grade. The comprehensive vision screenings, including investigation of binocularity and entailing distance VA measurements, are conducted on children in Grade 1, new scholars and those referred from Grade 2 and above. However, in Minnesota, comprehensive vision screenings are conducted on children in grades $2-5 .{ }^{39}$ The visual demands for children of school-going age from Grade 4 upwards when they are reading to learn are said to increase. ${ }^{11}$ Therefore, the benefit of evaluation of binocular visual skills at this age (i.e. in Grade 1) is questionable, and besides, there appears to be a challenge of comprehension and poor attention at this age when tests investigating binocularity are performed.

In the United Kingdom, school-entry (reception class) vision screenings do not appear to be included in the National Health Service (NHS) agenda of screening programmes. ${ }^{32}$ In the mid-1990s and early 2000s, periodic vision screening for preschool and school-age children occurred throughout the United Kingdom, conducted by public health nurses and orthoptists using a Snellen VA chart. Lack of evidence on benefits, insufficient resources to provide mass screenings, other public health priorities and budget cuts led to the discontinuation of these screening programmes. ${ }^{2}$

In Australia, the National Children's Vision Screening Project (NCVSP) of the Centre for Community Child Health (CCCH) established an expert Project Advisory Group (PAG) to advise on the planning and implementation of children's vision screening project. The PAG recommended that assessment of vision be undertaken at birth, between three and six months and at four years of age (one year prior to school commencement), disregarding the fact that rates of visual anomalies rise as children become older because of increased visual demands. ${ }^{7,29,36}$ In Oman, there is an annual screening of all children in early grades for active trachoma and other common eye diseases. Vision screenings in these countries therefore focus on evaluating vision, refractive errors and ocular pathologies. Vision is screened by nurses and refractionists using cycloplegic refraction, in preschools, and first secondary grades, thus ensuring that as children become older, their visual requirements are met. ${ }^{31}$

In South Africa, according to the implemented school vision screenings programme, screenings are conducted within the first year of entering primary school (Grade R/1), and again in Grade 4 and Grade 8 including children experiencing learning difficulties in any grade. In addition, all children in Grade 8 are also screened for visual anomalies, with tests including the nearpoint of convergence (NPC) and distance or near VA measurements. Furthermore, children experiencing learning difficulties in any grade are to be screened for visual anomalies including the investigation of vergence insufficiency. The recommended tests and the ages at which the evaluation of near visual skills is to be conducted mentioned in the reviewed South African Integrated School Health Policy (ISHP) are consistent with recommendations by Scheiman and Rouse. ${ }^{11,40}$ Remarkably, the inclusion of the evaluation of the near-vision functional skills appears to be appropriate for the detection of visual skills related to academic performance. However, the most important question to be asked is related to whether the vision screening personnel in the public sector are properly trained to conduct all the tests included in the programme.

\section{Vision functions screened}

In a recent policy statement, the American Academy of Optometry recommended that detection of significant refractive errors, amblyopia, strabismus and observable external ocular diseases should be considered for all ages when designing paediatric vision screenings. They further stated that vision screenings of pre-schoolers and children of school-going age may have to consider procedures that detect reduced visual function at near, as well as identify colour vision deficits in boys. ${ }^{37}$ According to legislation supported by Prevent Blindness, the elements of an authorised paediatric vision screening include, at a minimum, the observation checklist on appearance, behaviour and complaint signs, distance VA and refractive error (optional), stereopsis, colour vision, ocular alignment tests (cover test or NPC or Hirschberg) and appropriate follow-ups. ${ }^{32}$ Other states in the USA, such as Alaska, have considered the combinations of screening tests, which are generally associated with greater accuracy compared with single tests recommended by the US Preventive Services Task Force (USPSTF) ${ }^{41}$ These tests include the assessments of VA, stereoacuity, eyes alignment (cover test and Hirschberg), colour vision including the use of auto refractors and photoscreeners. Photoscreeners and auto refractors or any type of vision screening instruments serve as an adjunct to the traditional screening process. The support for the inclusion of the instruments in the school vision screenings is to improve the response rates in preverbal, preliterate and those children with developmental delays who are difficult to screen. ${ }^{42}$ In South Africa, according to the implemented school vision screenings programme, VA screenings are conducted within the first year of entering primary and all children in Grade 8 are screened for visual anomalies, with tests including the NPC and distance or near VA measurements. The recommended tests and the ages at which the evaluation of near visual skills is to be conducted as mentioned in the reviewed South African ISHP are consistent with recommendations by Scheiman and Rouse. ${ }^{11,40}$ Remarkably, the inclusion of the evaluation of the near-vision functional 
skills appears to be appropriate for the detection of visual skills related to academic performance. However, the most important question to be asked is related to whether the vision screening personnel in the public sector are properly trained to conduct all the tests included in the programme.

Distance visual acuity: Distance VA screening is the accepted method worldwide. It has been regarded as the 'gold standard' for decades, and continues to be effective when

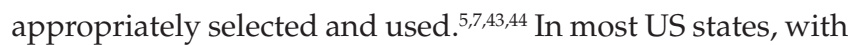
the exception of New York, Kansas and Missouri (Table 1), VAs are measured monocularly using the Sloan chart, because it was found to be more sensitive than the Snellen chart. Various screening programmes for the VA evaluation of children in preschool and Grade 1 use either the LEA symbols, the illiterate E, HOTV, Lighthouse or number charts. ${ }^{45,46,47}$ In most programmes, the assessment of uncorrected distance VA is relied upon to identify visual impairments such as amblyopia, refractive errors and anisometropia. However, in children of school-going age, the measuring of uncorrected VAs only was found to reliably detect myopia but not hyperopia or astigmatism. ${ }^{16}$

Vision screening protocols in the United Kingdom, Canada and Australia focus on the detection of amblyopia and strabismus by evaluating distance VA and ocular pathology. ${ }^{30,48,49,50,51}$ These aforementioned vision screening programmes appear to disregard investigating the presence of conditions such as uncorrected hyperopia (including latent hyperopia) vergence and accommodative dysfunction, found to be associated with reduced academic ability. Furthermore, these protocols seem to overlook risk factors for the development of strabismus and amblyopia, which may be caused by undetected anisometropia and uncorrected hyperopia.

Regardless of suggestions from various studies, including the Vision in Pre-schoolers (VIP) group study, for the inclusion of other tests in the vision screening protocols such as those evaluating near-vision functional skills and distance VA, the Snellen acuity chart is still widely used. ${ }^{52}$ With these calls largely ignored, there remains a consequential risk for binocular visual anomalies such as accommodative and vergence dysfunctions, including poor ocular motilities important in the learning capacity of children, remaining undetected. . $^{3,1}$

Near visual acuity: The importance of conducting near-vision screenings in schools in the literature reviewed remains a subject of debate. There appears to be consensus that nearvision assessment has merit when children with classroom difficulties are referred to the school nurse, particularly when they are struggling with reading. Failure of early detection of high hyperopia (significant farsightedness), if left untreated, can affect reading and learning.

The reason for lack of support of near VA evaluation is that children are born hyperopic, and the majority outgrow the condition. ${ }^{53}$ The preferred method included in most of the vision screening programmes for evaluating near-vision is the plus lens test, because of the inadequacy of the near-point VA measurements using the reading cards or charts. Young hyperopic children have often been found to successfully accommodate long enough to complete a test of near-vision when near acuity cards, charts or slides are used. ${ }^{54}$ In the United States, the strength of the plus lens used varies across the country. The $+2.50 \mathrm{D}$ lens is used in the states of New York, Alaska, California, Colorado and Iowa. ${ }^{46,55,56,57,58}$ In Pennsylvania, a 2.25 D lens is used to evaluate near-vision for the $5-8$ year olds, and a $1.75 \mathrm{D}$ lens is used for the those aged eight years and older. ${ }^{59}$ In Kansas and Tennessee, a $2 \mathrm{D}$ lens is used, with other states such as Missouri and Ohio not having included evaluation of near VAs in their vision screening protocols (Table 1). ${ }^{45,47,59,60,61}$

Binocular vision: Evidence has indicated that there is a link between vergence and accommodative dysfunction, including poor ocular motilities and poor educational outcomes, thus supporting the need for the vision screenings to include some of the tests that might detect vergence or accommodative problems. ${ }^{10,11,12,13,14,15}$ The American Academy of Optometrists, ${ }^{39}$ Prevent Blindness America ${ }^{32}$ and the Health Professions Council of South Africa (HPCSA ${ }^{62}$ have recommended that school vision screening programmes should focus on eye conditions that could potentially impact on children's ability to learn or affect their academic performance, in addition to detecting the risk factors of amblyopia.

Binocular vision tests, such as the cover test, NPC, Hirschberg and Randot E stereo test, are incorporated in most vision screening protocols of school-going age children in the United States, and in other countries, such as Canada; Hirschberg and the red reflex tests are for the infants and toddlers $^{32,39}$ (Table 1). In Australia, even though vision screenings are conducted on children of school-going age, there is major focus on screening children from the age of infancy to preschool ( $0-3.5$ years). Investigation of binocular anomalies in this age group includes the use of Hirschberg, cover test and the red reflex test. However, in other countries such as New Zealand, Australia and Canada, vision screening protocols for children of school-going age only assess distance VAs with parental questionnaires being utilised..$^{6,44}$ In the United Kingdom, as the main focus is on detecting amblyopia and its associated conditions, there is support for preschool vision screenings, and therefore their vision screening protocols include the evaluation of distance VAs only ${ }^{43,44,63}$ In South Africa, the NPC test is included in the vision screening protocol, and according to the ISHP, it is to be performed on children in Grade 8 and those referred because of apparent ocular anomalies or having learning problems. ${ }^{45}$

These tests (NPC, cover test, Hirschberg, stereo test and red reflex test) may have to be considered for inclusion in most school vision screening protocols to detect binocular visual anomalies and are recommended because they are easy, 
efficient and fast to perform, including the fact that they are inexpensive. Nonetheless, the training of vision screeners to conduct the tests is important in order to avoid high falsepositive and false-negative referrals.

Colour vision: Tests assessing colour vision are not always included in the school vision screening batteries on the premise that congenital colour vision defects are untreatable. In addition, the role of colour vision defects in the learning process still has to be determined. ${ }^{6}$ Consistent with this statement, Proctor in Department of Education (Colorado 2006) recommended that colour vision testing need not be a required screening procedure, because colour deficiency is usually not progressive, cannot be corrected and usually does not affect VA or visual function. ${ }^{64}$ However, colour vision screening tests are included in most of the US vision screening protocols, with the recommendation that they should be evaluated on boys only (Table 1). As stated in most vision screening protocols, the outcome of colour vision tests is not for referral purposes but for informing parents, schools and children on career guidance. However, parents, teachers and counsellors are to be informed with the outcome of the colour deficiency screenings, with the aim that educational materials may be adjusted for those children found to have colour vision defects. ${ }^{27}$

Instruments: A joint policy statement titled 'InstrumentBased Pediatric Vision Screening Policy Statement' was issued by the American Academy of Pediatrics (AAP), the American Academy of Ophthalmology (AAO), the American Association for Pediatric Ophthalmology and Strabismus (AAPOS) and the American Association of Certified Orthoptists (AACO). In this joint policy statement, reference was made to the fact that instrument-based vision screenings are quick, child cooperation required is minimal and can be beneficial in preverbal, preliterate or developmentally delayed children. ${ }^{65}$ In addition, the evolution of modern technology has led to the development of numerous mobile computing applications that demonstrate the efficacy in screening visual skills. Growing demand and interest in the usage of modern technologies (e.g. EyeSpy and Spectrum) is because of their ease of use and expediency, although there are concerns about the costs of such programmes and their validity. ${ }^{63,66,67}$

Stereoscopic instruments such as the Bausch \& Lomb School Vision Tester, Keystone Telebinocular Screener, Titmus Vision Screener and Massachusetts battery of tests in the United States are nationally recommended in the majority of the school vision screening programmes ${ }^{50,55,56,57,58,60,61,68}$ (Table 1). Meanwhile, in other places such as South Africa and Connecticut, they appear not to be used in the public sector for mass screenings (by school health nurses) but can be used by the optometrists, ophthalmologists, optical dispensers and medical practitioners in their private practices. ${ }^{40,69}$ Nonetheless, in the state of Georgia (Cobb), vision screening instruments (e.g. Titmus machines or Spot screeners) are recommended, with the warning on the inability to observe the child's face and eyes during testing when these instruments are used. HOTV test in the vision screening programme of Georgia is clearly stated as a legally approved means of vision screening for the assessment of poor distance VAs. ${ }^{70}$ Instrument-based vision screening in the United States includes photoscreeners (e.g. Plus Optix) for the preschool population and is supported by the AAP in the absence of sufficient evidence base. ${ }^{65}$ Conversely, it can benefit children younger than four years and VA testing can be used reliably on older children. Affordability could be the only problem for this method of vision screening to be used in the US national programmes or in the South African school vision screening programme. Nonetheless, there is a need for further research to investigate the validity of such programmes, including the computer software.

Criteria for referral: There are varying opinions relating to the most suitable VA level used as the cut-off for referral. However, lack of research on the impact mild vision impairment has on the functional ability and quality of life in children is not known. While the literature recommends a VA worse than 6/9 $(20 / 30)$ as the cut-off referral criterion, most screening programmes in the United States for children in Grade 1 and older use the referral criterion of 6/9 (20/30) or worse, and for the pre-schoolers, 6/12 (20/40) or worse or two or more lines of difference between the two eyes. ${ }^{32}$ In California, the cut-off for referral is $6 / 15(20 / 50)$ or worse for pre-schoolers, and $6 / 12(20 / 40)$ or worse for children of school-going age $\mathrm{e}^{56}$ (Table 1). The referral criteria on children's vision screenings in most parts of the United States come from the AAP. ${ }^{65}$

In order to match the recommended criteria with those of the AAP, a National Association of Nursing document is utilised as a resource for school health nurses in most states, for example, in New York, Colorado and California. ${ }^{71}$ The lower the criteria (e.g. worse than $6 / 7.5$ or $6 / 6$ ), the higher the false referrals, and the higher the criteria $(6 / 9.5$ or $6 / 12)$, the lower the false referrals. ${ }^{54}$ The selection of proper referral criteria is essential, despite worldwide differences in the criteria used to pass vision screenings.

Vision screening personnel: School health nurses are considered capable screeners in most countries, namely, the United States, South Africa, Australia, Canada, India and East Mediterranean Regions, provided that they undergo training and the referral protocols are followed. ${ }^{29,30,31,40}$ In the US states, such as Colorado, Kansas, Nevada, New Jersey and Montana, and in countries such as India where there are limited numbers of nurses, the training of appropriately qualified personnel (teachers, parents, primary care health providers and lay eye screeners) available within a jurisdiction is recommended, with the aim of ensuring accuracy of the screenings. $5,17,45,57,72$. However, in other countries, such as the United Kingdom, orthoptists are the preferred personnel to conduct primary vision screenings. ${ }^{7,26}$

In a study in India, the involvement of trained teachers in conducting vision screenings was found to be very effective in terms of coverage, and less costly compared to the PHC model. ${ }^{73}$ 
Performance of school vision screenings by optometrists and ophthalmologists appears not to be supported in other countries. ${ }^{27,71}$ The reason for not supporting the school vision screenings conducted by the eyecare professionals was related to concerns raised that they are most likely to perceive the screenings as formal eye examinations, or even as a form of solicitation. Nonetheless, it was acknowledged that the best screening methods are those that employ professionally trained optometrists. ${ }^{71}$ In the school health policy of Washington, D.C., it is stated that school vision screenings may not be performed by ophthalmologists, optometrists or opticians, or any individuals who may have a conflict of interest. ${ }^{27}$ Staffing patterns of school health programmes depend on needs analysis and the availability of human and financial resources. ${ }^{5}$

\section{Limitations of the review}

The following are the limitations of this review:

- The review was based on the vision screening policies and guidelines, and most of these policies were not supported by any epidemiological research.

- The ideal test or combination test for school-going age populations was not established, because different methods were used worldwide with the evaluation of distance VAs supported worldwide.

- The literature on the prevalence of visual anomalies among the school-going age did not provide the researcher with the appropriate combination tests to be included in the vision screening programmes, because different methods were used for the different age groups.

- Most of the literature reviewed on the prevalence of near visual functions was on clinical populations versus the normal school-going populations, therefore not providing accurate statistics on the prevalence of near visual functions among children of school-going age.

\section{Recommendations for future studies}

The following are the recommendations for future studies:

- High-quality multi-stage random trials investigating the visual status of neurologically normal children with reading and writing difficulties.

- The appropriate method investigating the subsequent impact of improvements in functional vision and improved education outcomes including quality of life.

- Evaluation of the impact of different screening methods administered by various personnel in a variety of settings, to determine the ideal reasonable test or combination tests to be included in the vision screening programme.

- Large random cluster or stratified trials in South Africa investigating the prevalence of visual anomalies among children of school-going age in the foundation, intermediate and senior phases of learning.

- The effect of different strengths of plus lenses that can detect latent hyperopia, including the length of time required to detect this condition.

- Investigation of the validity of using the computer software for mass screenings including school vision screenings.
- Investigation of the financial implications of using the computer software programmes for mass screenings including school vision screenings.

\section{Conclusion}

Evidence in the literature reviewed indicated that the purpose of conducting vision screening in schools worldwide is focused on detecting amblyopia and its risk factors. The increased visual demand as children progress through their school years is not considered when vision screening protocols are developed, even though the literature has shown a link between poor visual skills and learning performance. The lack of evidence related to the effect of investigating other visual anomalies (such as binocular anomalies) besides amblyopia appears to have contributed towards the differences in the age criteria for vision screening protocols. The motivation for the vision screening of pre-schoolers is attributed to lack of evidence of benefits related to vision screenings conducted on the children of school-going age, and insufficient financial and human resources to provide mass screening. These factors appear to have led to vision screenings being focused only on evaluating younger children from birth to three years, and disregarding the school-going age population. In other countries, action taken to ensure that early vision screenings take place seem to serve as a gatekeeping process, guaranteeing that school-going age children do not present with visual anomalies at a later stage. Screening by appropriately trained non-vision health professionals, such as nurses, teachers and parents, and the option for secondary screening by the optometrists or ophthalmologists was suggested by the evidence.

\section{Acknowledgements}

The authors wish to acknowledge Prof. T.A. Rasengane for her contributions towards the drafting and editing of this manuscript.

\section{Competing interests}

The authors declare that they have no financial or personal relationships that may have inappropriately influenced them in writing this article.

\section{Authors' contributions}

I.T.M. was PhD student of the study. W.J. who supervised the PhD studies has led to the drafting of this manuscript. R.H. who was the co-supervisor of the study and has contributed immensely in the editing of this manuscript. E.W.N. was cosupervisor of the PhD study.

\section{References}

1. Wilson JMG, Jungner G. Principles and practice of screening for disease. Public Health Paper No. 34. Geneva: WHO; 1968, p. 1-163.

2. Solebo AL, Rahi JS. Vision screening in children aged $4-5$ years. External review against programme appraisal criteria for the United Kingdom National Screening Committ. 2013, p. 1-48. [cited 2015 Jun 29]. Available from: https:// legacyscreening.phe.org.uk/policydb_download.php?doc=365 
3. Zaba JN. Children's vision care in the 21st century and its impact on education, literacy, social issues, and the workplace: A call to action. I Behav Optom. 2011;22(2):39-41.

4. Kleinstein RN, Jones $\mathrm{LA}$, Hullet $\mathrm{S}$, et al. Refractive error and ethnicity in children JAMA. 2003;121(8):1141-1147. https://doi.org/10.1001/archopht.121.8.1141

5. Ferebee A. Childhood vision: Public challenges and opportunities [homepage on the Internet]. A policy brief. School of Public Health and Health Services. The George Washington University Medical Center. 2004. [cited 2017 Jun 26]. Available from: http://www.healthinschools.org/wp-content/uploads/2016/10/visionfinal.pdf

6. Logan SL, Gilmarth B. School vision screening, ages 5-16 years: The evidence-base for content, provision and efficacy. Literature review. Ophthal. Physiol. 2004;24:481-492. https://doi.org/10.1111/j.1475-1313.2004.00247.x

7. Mathers $M$, Keyes $M$, Wright $M$. A review of the evidence on the effectiveness of children's vision screening. Child Care HIth Dev. 2010;36(6):756-780. https://doi. org/10.1111/j.1365-2214.2010.01109.x

8. Shin HS, Park SC, Park CM. Relationship between accommodative and vergence dysfunctions and academic achievement for primary school children. Ophthal. Physiol. Opt. 2009;29:615-624. https://doi.org/10.1111/j.1475-1313.2009. 00684.x

9. Palomo-Alvarez C, Puell MC. Accommodative function in school children with reading difficulties. Graefes Arch Clin Exp Ophthalmol. 2008;246:1769-1774. https://doi.org/10.1007/s00417-008-0921-5

10. Oberholzer M, Nel M, Hartely S, Maartens M, Pheiffer C, Nonkula M, Steyn A. Visual acuity, amplitude of accommodation and near point of convergence and academic achievement in primary school learners in Bloemfontein. S Afr Optom. 2014;73(1):33-38.

11. Scheiman MM, Rouse MW. Optometric management of learning related vision problems. 2nd ed. St Louis, MO: Elsevier, Mosby, 2006; p. 215.

12. Naidoo KS, Raghunandan A, Mashige KP, et al. Refractive error and visual impairment in African children in South Africa. Inv Ophthal Vis Sci. 2003;44(9):3764-3770. https://doi.org/10.1167/iovs.03-0283

13. Gursoy H, Basmak H, Yaz Y, Colak E. Vision screening in children entering school: Eskisehir, Turkey. Ophthalmic Epidemiol. 2013;20(4):232-238. https://doi.org/10. 3109/09286586.2013.808672

14. Wu JF, Bi HS, Wang SM, et al. Refractive error, visual acuity and causes of vision loss in children in Shangdong, China. PLoS One [serial online]. 2013. [cited 2017 Jul 25];8(12):e82763. Available from: http://www.plosone.org.strabismus

15. Matsuo T, Matsuo C. The prevalence of strabismus and amblyopia in Japanese elementary school children. Ophthalmic Epidemol. 2005;12(1):31-36. https://doi. org/10.1080/09286580490907805

16. O'Donoghue L, McClelland JF, Logan NS, et al. Profile of anisometropia and anisoastigmatism in children: Prevalence and association with age, ocular biometric measures, and refractive status. Invest Ophthalmol Vis Sci. 2013;54(1):602-608. https://doi.org/10.1167/iovs.12-11066

17. Lam CS, Lam C, Cheng SC, Chan LY. Prevalence of myopia among Hong Kong Chinese schoolchildren. Ophthalmic Physiol Opt. 2012;32(1):17-24. https://doi. org/10.1111/j.1475-1313.2011.00886.x

18. Ostadimoghaddam $\mathrm{H}$, Fotouhi $\mathrm{A}$, Hashemi $\mathrm{H}$, et al. Prevalence of the refractive errors by age and gender: The Mashhad eye study of Iran. Clin Exp Ophthalmol. errors by age and gender: The Mashhad eye study of Iran. Clin Exp Ophthat
2011;39(8):743-751. https://doi.org/10.1111/j.1442-9071.2011.02584.x

19. Mabaso R, Oduntan A, Mpolokeng M. Refractive status of primary school children in Mopani district, Limpopo province, South Africa. S Afr Optom. 2006:65:125133. https://doi.org/10.4102/aveh.v65i4.263

20. Borsting E, Rouse MW, Deland PN, et al. Association of symptoms and convergence and accommodative insufficiency in school-age children. Optometry. 2003;74(1):25-34.

21. Abdi S, Lennerstrand G, Pansell T, Rydberg A. Orthoptic findings and asthenopia in a population of Swedish schoolchildren aged 6 to 16 years. Strabismus. 2008;16(2):47-55. https://doi.org/10.1080/09273970802020243

22. Dusek W, Pierscionek B, McClelland J. A survey of visual function in an Austrian population of school-age children with reading and writing difficulties. BMC Ophthalmol. 2010;10(1):16-16. https://doi.org/10.1186/1471-2415-10-16

23. Wajuihian SO, Hansraj R. Near vision anomalies in black high school children in Empangeni, South Africa: A pilot study. S Afr Optom. 2014;73(1):21-32. https:// doi.org/10.4102/aveh.v73i1.4

24. Moodley VR. Amplitude, facility and accuracy of accommodation in a primary school population. S Afr Optom. 2008;67(4):147-154. https://doi.org/10.4102/ aveh.v68i4.196

25. Benzoni JA, Rosenfield M. Clinical amplitude of accommodation in children between 5 and 10 years of age. OVD. 2012;43(3):109-114.

26. Toufeeq A, Oram AJ. School-entry vision screening in the United Kingdom: Practical aspects and outcomes. Ophthal Epi. 2014;21(4):210-216. https://doi.org/ 10.3109/09286586.2014.906627

27. Prevent Blindness America. Eye problems in adults and children. 2017 [cited 2016 Feb 09]. Available from: https://www.preventblindness.org/eye-problems-adultschildren

28. Hatch SW. Optometric care within the public health community. Vision screening Cadyville, NY: Old Post Publishing; 2009, p. 1-22.

29. Hopkins S, Sampson GP, Hendicott P, Wood JM. Review of guidelines for children's vision screenings. Clin Exp Optom. 2013;96:443-449. https://doi.org/10.1111/ cxo.12029

30. Mema SC, Mcintyre L, Musto R. Childhood vision screening in Canada: Public health evidence in practice. Can J Public Health. 2012;103(1):40-43.
31. Eastern Mediterranean Regional office of the International Agency for the Prevention of Blindness (EMR-IAPB). Guidelines for school eye health for the Eastern Mediterranean Region (EMR) [homepage on the Internet]. 2009. [cited 2016 Feb 15]. Available from: https://www.iapb.org/.../guidelines-for-school-eye2016 Feb 15]. Available from: https://wWW.iapb.or
health-in-the-eastern-mediterranea...MR-IAPB

32. Fathy VC, Elton PJ. Orthoptic screening for three- and four-year-olds. J. Public Health. 1993;107:19-23. https://doi.org/10.1016/S0033-3506(05)80488-3

33. Kvarnström $G$, Jakobsson $P$, Lennerstrand $G$. Visual screening of Swedish children: An ophthalmological evaluation. Acta Ophthalmol Scand. 2001;79(3):240-244. https://doi.org/10.1034/j.1600-0420.2001.790306.x

34. Atkinson J, Braddick O, Robier B, et al. Two infant vision screening programmes: Prediction and prevention of strabismus and amblyopia from photo- and videorefractive screening. Eye (Lond). 1996;10:189-198. https://doi.org/10.1038/eye.1996.46

35. Hall DMB, Elliman D. Health for all children. Oxford University Press: Oxford; 2003.

36. Centre for Community Child Health. National children's vision screening project [homepage on the Internet]. Discussion paper. Melbourne: Centre for Community Child Health; 2008. [cited 2017 Jun 13]. Available from: https://www.rch.org.au/ uploadedFiles/Main/Content/ccch/DiscussPaper_VisionScreenProject.pdf

37. American Academy of Optometry. Policy statement childhood vision screening [homepage on the Internet]. 2016. [cited 2016 Jul 18]. Available from: https:// www.aaopt.org/

38. Bright Futures Peridiocity [homepage on the Internet]. 2001. [cited 2016 Jul 19] Available from: http://brightfutures.org/pocket/pdf/appendices.pdf. Child and Teen Checkups (C, CT). Periodicity schedule. (n.d.) http://www.edocs.dhs.state. Teen Checkups (C, CT). Periodicity sched
mn.us/Ifserver/Public/DHS-3379-ENG

39. Minnesota Department of Health (MDH). Vision screening guidelines for infancy, childhood and School age children [homepage on the Internet]. 2017. [cited $2016 \mathrm{Jul}$ 25]. Available from: http://www.health.state.mn.us/divs/cfh/topic/ visionscreening/content/document/pdf/visionscrnman.pdf

40. National Department of Health. The integrated school health policy. Pretoria: Government Printer [homepage on the Internet]. 2012. [cited 2017 Aug 02]. Available from https://www.health-e.org.za/2013/10/24/integrated-school-health-policy/

41. United States Preventive Services Task Force (USPSTF). Guide to clinical preventive services: Screening for visual impairment in children ages 1 to 5 [homepage on the Internet]. 2014. [cited 2018 Feb 15]. Available from: https://www.ncbi.nlm. nih.gov/books/NBK235846/

42. American Academy of Ophthalmology. Joint Policy Statement. Vision screening for infants and children [homepage on the Internet]. American Academy of Ophthalmology: San Francisco, CA; 2013. [cited 2016 May 10]. Available from https://aapos.org

43. Ethan D, Basch CE. Promoting healthy vision in students: Progress and challenges in policy, programs, and research. J Sch Health. 2008;78(8):411-414. https://doi org/10.1111/j.1746-1561.2008.00323.x

44. McNamara R. Vision screening: A benchmarking audit. Br Ir Orthopt J. 2008;5:65-68.

45. Kansas Department of Health and Environment Bureau for Children, Youth and Families. Vision screening guidelines for infants, toddlers, children and youth [homepage on the Internet]. 5th ed. 2004; p. 1-65. [cited 2016 Mar 28]. Available [homepage on the Internet]. 5th ed. 2004; p. 1-65. [cited 2016 Mar 28]. Ava
from: http://www.kdheks.gov/bfh/download/VisionGuidelines2004.pdf

46. The State Education Department. School vision screening guidelines [homepage on the Internet]. The University of the State of New York. 2011. [cited 2016 Feb 12]. Available from: http://www.p12.nysed.gov/sss/schoolhealth/schoolhealthservices/ Available from: http://www.p12.nys

47. Missouri Department of Health and Senior Services (M.D.o.H.a.S.). Guidelines for vision screening in Missouri schools [homepage on the Internet]. 2014 [cited 2016 Feb 22]. Available from: http://health.mo.gov/living/families/schoolhealth/pdf/ Feb 22]. Available from: http://h
VisionScreeningGuidelines.pdf

48. Weinstock VM, Weinstock DJ, Kraft SP. Screening for childhood strabismus by primary care physicians. Can Fam Physician [serial online]. 1998. [cited 2016 Feb 29];44:337-343. Available from: https://www.ncbi.nlm.nih.gov/pmc/articles/ PMC2277602/pdf/canfamphys00048-0131.pdf

49. Canadian Task Force on Preventive Health Care. New grades for recommendations from the Canadian Task Force on Preventive Health Care. CMAJ [serial online]. 2003. [cited 2016 Feb 22];169(3):207-208. Available from: https://webcache. googleusercontent.com/search?q=cache:khC3f6NQl88J:https://canadiantaskforce. $\mathrm{ca} /+\& \mathrm{~cd}=1 \& \mathrm{hl}=$ en $\& \mathrm{ct}=\mathrm{clnk} \& \mathrm{gl}=\mathrm{za}$

50. Graham T. Report prepared for the Healthy Children, Women, Seniors BC Ministry of Health Services [homepage on the Internet]. A review of the science underlying preschool vision screening with implications for BC. 2005. [cited 2016 Jun 22]. Available from: https://www.health.gov.bc.ca/library/publications/year/2005/ Final-PreschoolVisionOct31.pdf

51. Optometrists Association Australia. Position statement: Vision screenings [homepage on the Internet]. 2009 [cited 2017 Mar 09]. Available from: http:// www.optometry.org.au/media/278175/position_statement_vision_screenings

52. The Vision in Preschoolers Study Group. Comparison of preschool vision screening tests as administered by licensed eye care professionals in the vision in preschoolers study. Ophthalmol. 2004;3(4):637-650.

53. Duckman RH. Visual development diagnosis, and treatment of the pediatric patient. 1st ed. New York: Lippincott Williams and Wilkins, 2006; p. 80.

54. Rosenbloom AA, Morgan MW. Principles and practice of pediatric optometry. Philadelphia: J.B. Lippincott Co., 1990; p. 479.

55. Alaska Division of Public Health. Near-vision screening procedure. In: Vision screening guidelines for the preschool/school population [homepage on the
Internet]. Anchorage, AK: Department of Health and Social Services. 2013. [cited 2016 Feb 19]. Available from: http://dhss.alaska.gov/dph/wcfh/Documents/ 2016 Feb 19]. Available from: http://dhss.alaska.gov/dph/wcfh/D
school/VisionScreeningGuidelinesPre-schoolSchoolPopulation.pdf 
56. California department of Education. A guide for vision testing in California public schools [homepage on the Internet]. California Department of Education. 2005. [cited 2016 Feb 20]. Available from: http://www.cde.ca.gov/ls/he/hn/documents/ visionreport.pdf

57. Colorado Department of Education. Guidelines for school vision screening programs: Kindergarten through to Grade 12 [homepage on the Internet]. 2006.
[cited 2016 Feb 19]. Available from: https://www.cde.state.co.us/sites/default/ files/documents/healthandwellness/download/nurvisionguidelines.pdf

58. University of lowa. Department of Ophthalmology Vision Screening Guidelines, Children's vision screening and intervention. 2010 [cited 2016 Feb 20]. Available from https://iowa.preventblindness.org/childrens-vision- screening-and-intervention

59. Zimmerman RS. Procedures for the vision screening program for Pennsylvania school-age population [homepage on the Internet]. Philadelphia, PA: Department of Health. 2002. [cited 2016 Feb 23]. Available from: http://pennsylvania.aoa.org/ documents/PA-DOH-SchVisScr-Proc.pdf

60. Tennessee Department of Education. Tennessee school health screening guidelines [homepage on the Internet]. 2008. [cited 2016 Feb 24]. Available from: http://www.tennessee.gov/assets/entities/education/attachments/csh_school health_screening_guidelines.pdf

61. Department of Health (Ohio). Vision screening requirements and guidelines for school-aged children [homepage on the Internet]. Ohio Department of Health 2004. [cited $2016 \mathrm{Feb} 18$ ]. Available from: http://www.odh.ohio.gov

62. Health Professions Council of South Africa (HPCSA). Professional board for optometrists and dispensing opticians [homepage on the Internet]. Guidelines to
vision screening, itinerant practices and mobile clinics. 2007. [cited 2017 Mar 10]. Available from: http://www.hpcsa.co.za/Uploads/editor/UserFiles/downloads/ optometry/vision_screening_12_09.pdf

63. Sun JK, Aiello LP, Cavallerano JD, et al. Visual acuity testing using autorefraction or pinhole occluder compared with a manual protocol refraction in individuals with diabetes. Ophthalmol. 2011;118(3):537-542. https://doi.org/10.1016/j.ophtha. 2010.07.022

64. Proctor S. To see or not to see. Screening the vision of children in school [homepage on the Internet]. In: Colorado Department of Education. Guidelines for schoo vision Screening. 2006. [cited 2017 Jan 28]. Available from: http://www.cde.state. co.us/sites/default/files/documents/healthandwellnes/download/nursvisiong
65. American Academy of Pediatrics. Policy statement. Role of the school nurse in providing school health services. J. Pediatr [serial online]. 2008. [cited 2015 Feb 03];121(5):1051-1056. Available from: http://www.pediatrics.org/cgi/doi/ 10.1542/peds.2008-0382

66. Perera C, Chakrabarti R, Isla, FMA, Crowston J. The eye phone study: Reliability and accuracy of assessing Snellen visual acuity using smartphone technology. Eye (Lond). 2015;29(7):888-894. https://doi.org/10.1038/eye.2015.60

67. Trivedi RH, Wilson ME, Petersei MM, Cole KB. Teed RGW. A pilot study evaluating the use of EyeSpy video game software to perform vision screening in school-aged children. J AAPOS. 2010;14(4):311-316. https://doi.org/10.1016/j.jaapos.2010. 03.008

68. Arizona Department of Health Services. Recommended vision screening guidelines for children ages 3 and older [homepage on the Internet]. 2010. [cited 2016 Feb 16]. Available from: https://www.visionquest2020.org/secure/ GD-100-PHS-WCH.pdf

69. Connecticut State Department of Education. Guidelines for health screenings: Vision, postural, hearing [homepage on the Internet]. 2004. [cited 2016 Feb 19]. Available from: http://www.sde.ct.gov/sde/lib/sde/PDF/deps/student/health/ Guidelines_Health_Screenings_CSDE.pdf

70. Cobb county school district (Georgia). Mass vision screening program 2017-2018 [homepage on the Internet]. (n.d.); [cited 2016 Mar 11]. Available from: http:// www.cobbk12.org/centraloffice/academics/specialstudents/hearingvision/ Vision\%20Screening\%20Manual_2015-2016.doc

71. American Optometric Association (n.d). A school health nurse's guide to vision screening and ocular emergencies. St Louis, MO: American Optometric Association Clinical Care and Communications Groups American Foundation for Vision Awareness (AFVA)

72. Priya A, Veena K, Thulasiraj $R$, et al. Vision screening by teachers in southern Indian schools: Testing a new "all class teacher" model. Ophthalmic Epidemiol. 2015;22(1):60-65. https://doi.org/10.3109/09286586.2014.988877

73. Sudhan A, Pandey A, Pandey S, Srivastava P, Pandey KP, Jain BK. Effectiveness of using teachers to screen eyes of school-going children in Satna district of Madhya Pradesh, India. Indian J Ophthalmol. 2009;57(6):455-458. https://doi.org/10. 4103/0301-4738.57157 